\title{
Ice skating injuries: can they be reduced or prevented?
}

\author{
C. D. H. OAKLAND
}

Basingstoke District Hospital, Basingstoke, Hampshire, England

\section{SUMMARY}

The opening of an ice rink resulted in 469 attendances at the local Accident and Emergency department over the first year. One hundred and eight had a significant injury. Thirty-seven patients were admitted. Thirty-three required an operation under general anaesthesia. Thirty had consumed alcohol at the rink's bar. Nine of these had a fracture. The number of skaters attending the Accident and Emergency department per 1000 visits to the rink declined over the study period. Injuries could be reduced if protective clothing was worn. Alcohol should not be sold at the rink. First aid although effective could be improved.

\section{INTRODUCTION}

Ice skating has become a popular leisure activity over the last few years and the risks are generally not well appreciated.

\section{MATERIALS AND METHODS}

All patients attending the Accident and Emergency department at Basingstoke District Hospital who were injured at the Basingstoke ice rink during the first year of its operation were studied prospectively.

Correspondence: C. D. H. Oakland FRCS, Senior Registrar in Accident E Emergency Medicine, Basingstoke District Hospital, Basingstoke, Hampshire RG24 9NA, England 


\section{RESULTS}

Age and pattern of attendance

There were 228382 attendances at the Basingstoke ice rink over the 12-month study? period. A total of 469 patients sought treatment at the Accident and Emergency $\underset{\vec{s}}{\overrightarrow{0}}$ department following a skating injury. The details of 462 were traced and analysed.o The sex distribution was equal (241 male, 223 female). The total number of visits to the ice rink was compared with attendances at Accident and Emergency month by month and there was no correlation $(r=0 \cdot 181)$. There was however a significant 0 negative correlation between Accident and Emergency attendances per 1000 visits to the ice rink over the study period $(r=0.651, p=0.030)$, i.e., there were fewer skaters $\vec{O}$ injured per 1000 visits to the ice rink at the end of the study period than at the start $\vec{\omega}$ (Fig. 1). The age range was from 3 to 62 , the median age was 16 years and $63 \%$ were aged 11-20.

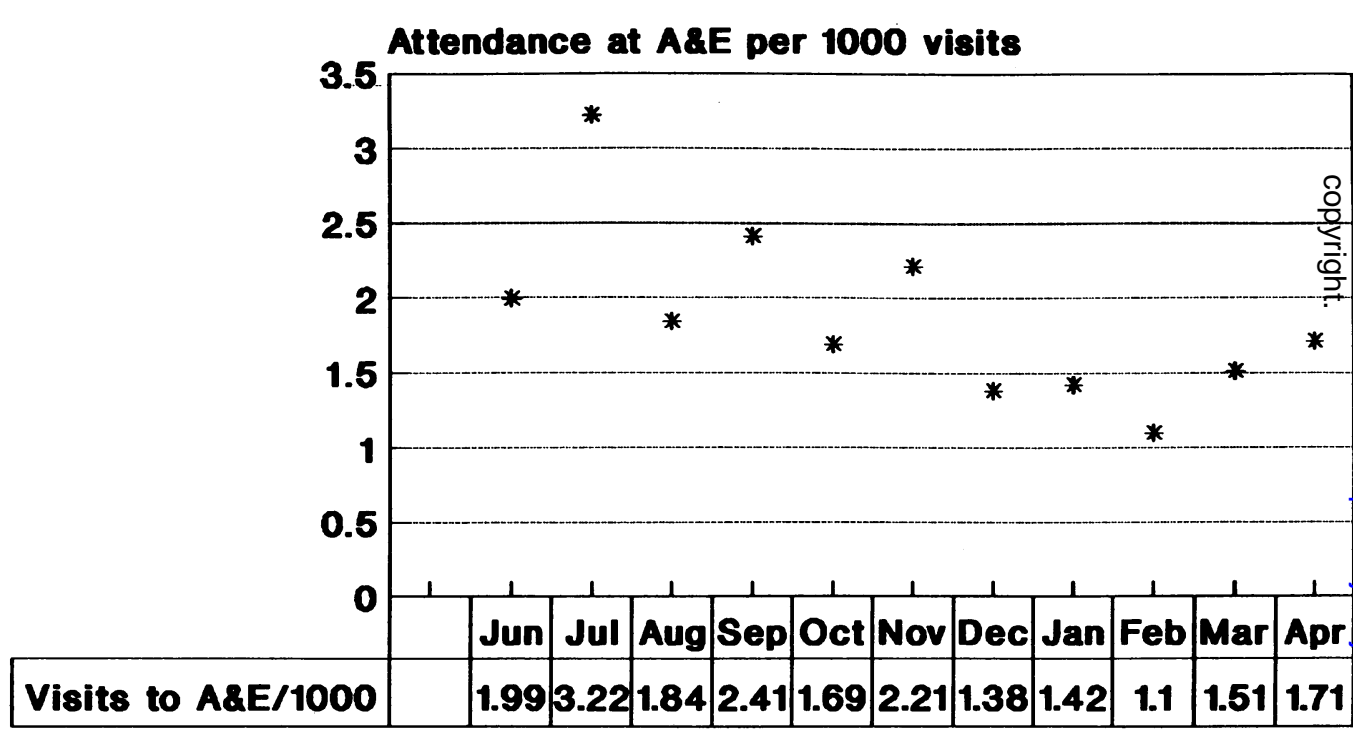

* Visits to A\&E/1000

$r=-0.651(p=0.03)$

Fig. 1 Correlation between number of patients seen in A \& E per 1000 visits to the rink over study period. 
$X$-rays

Three hundred and thirty-three $(70 \%)$ of attendances were X-rayed, of which 82 were adjudged abnormal by the Senior House Officers (25.4\%). The error rate as expressed as a percentage of missed significant positives was $0.83 \%$.

\section{Significant injuries}

There were 77 fractures and 8 dislocations. The wrist and upper arm predominated $(75 \%)$. The distribution of injuries is depicted in (Fig. 2). The mean age of this group was 29.5 years (SD 12.6); this is significantly older than the total group $(p=0.070$ same variance, t-test $p=0.000$ ). Only 41 were seen by a first aider and 16 came by ambulance. Twenty-five identified predisposing factors to their injury including 9 who had consumed alcohol at the rink's bar. In this group 33 skaters required an operative procedure under anaesthesia. Twenty-three patients required admission as a result of head injury; they were discharged the next day after an uneventful period of observation. There were no skull fractures. Five had consumed alcohol prior to their injury. Eight were children and were admitted to the paediatric unit.

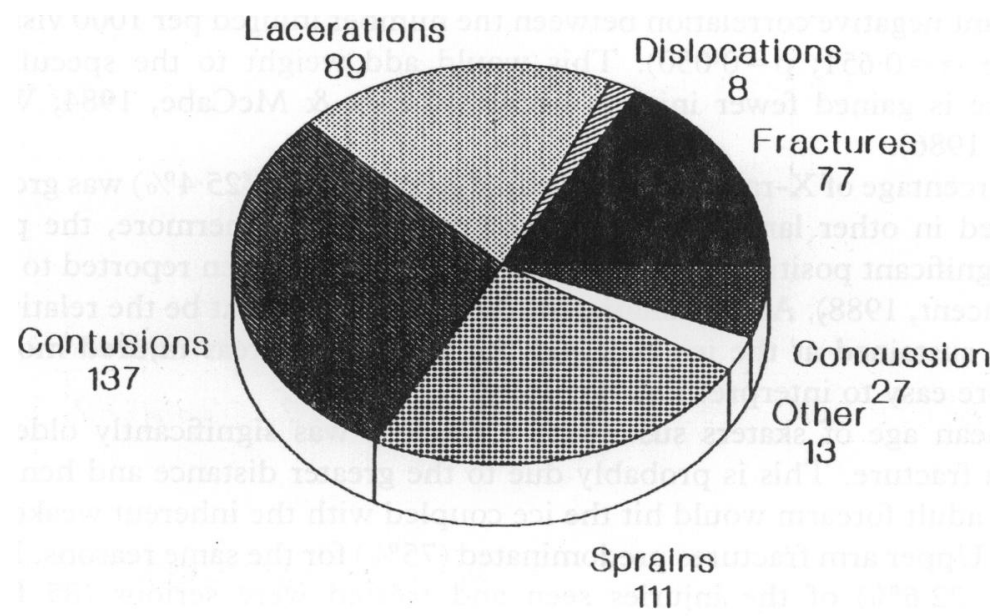

Total $n=462$

Fig. 2 Distribution of injuries sustained at rink. 
First aid at the rink

The first aiders attended 768 skaters over the study period. Approximately $50 \%$ were referred to hospital, the majority took this advice. Of the 85 patients sustaining fracture or dislocation only 41 were seen by a first aider.

\section{Predisposing factors to injury}

A total of 116 patients identified some predisposing factor contributing to their injury $\frac{\frac{\sigma}{\bar{\phi}}}{\bar{\phi}}$ Thirty had consumed alcohol on the premises and 19 said that the ice was in poor condition, being either very rutted or slushy. These accidents all occurred towards the end of each skating session. Seventeen volunteered that the rink was very crowded and $\vec{P}$ 14 were pushed over from behind. Hired boots were implicated in 8 accidents. A total of $\vec{\psi}$ 25 fractures occurred in this group and in 10 of these the predisposing factor was the ingestion of alcohol.

\section{DISCUSSION}

Other studies have shown the effect of a newly opened ice rink on the local accident andচ emergency department (Prescott, 1986; Williamson \& Lowdon, 1986; Freeland, 1988). $\vec{\bullet}$ This is the longest study from the United Kingdom. The initial flood of injuries segn immediately after the opening of the rink, quickly reduced to around 30 per month clustered at weekends. The total numbers represented $1.8 \%$ of attendances. There a significant negative correlation between the number injured per 1000 visits to the rink $k$ over time $(r=0.651 ; p=0.030)$. This would add weight to the speculation that aso experience is gained fewer injuries occur (Horner \& McCabe, 1984; Williamson $\&_{\vec{P}}^{\circ}$ Lowdon, 1986).

The percentage of X-rays taken and adjudged abnormal $(25 \cdot 4 \%)$ was greater than has been noted in other larger studies (Vincent, 1988). Furthermore, the percentage of missed significant positives was $0.83 \%$, whereas this has been reported to be as high as $39 \%$ (Vincent, 1988). An explanation of these findings might be the relative severity of an injury sustained at the ice rink and the anatomical areas injured most frequently. being more easy to interpret radiologically.

The mean age of skaters sustaining a fracture was significantly older than those without a fracture. This is probably due to the greater distance and hence force with? which an adult forearm would hit the ice coupled with the inherent weakening of bone with age. Upper arm fractures predominated (75\%) for the same reasons. It can be seen that $105(22.6 \%)$ of the injuries seen and treated were serious (85 fractures ando dislocations, and 20 significant head injuries). First aiders at the rink referred about $50 \%$ of skaters who sought their help to hospital, although not all heeded this advice. W Thus, they had a pre-hospital filtering effect, which has been observed before $\sigma$ (Williamson \& Lowdon, 1986). However they only attended $50 \%$ of those who? sustained a fracture and furthermore, of the 88 sent by them to hospital by ambulance, $56(64 \%)$ were discharged with no follow up, indicating a minor injury. There is thus at need for more highly trained paramedical staff. 
All previous reports (Horner \& McCabe, 1984; Prescott, 1986; Williamson \& Lowdon, 1986; Bernard et al., 1988; Freeland, 1988) have stressed that a large number of injuries could have been avoided if suitable protective clothing had been worn. Despite this good advice only 10 of our patients used any such apparatus.

This study attempted to identify any predisposing factors which contributed to a skater's injury. Thirty of our patients had consumed alcohol on the premises and of these 10 had a fracture and 5 required admission as a result of head injury. The next most common factor was poor ice conditions, which has been identified before in a large Swiss study (Biener \& Muller, 1973). It is the usual practice at ice rinks to divide up the skating into sessions with time in between to clear and smooth the ice. It would appear that these sessions might be reduced in length, particularly at busy weekend periods.

In the current climate of the National Health Service it would seem reasonable for the management of ice rinks to make recompense to the district health authorities for the cost of treatment of skaters injured at their rinks, indeed this may have the effect of keeping safety measures a top priority.

\section{REFERENCES}

Freeland P. (1988) Implications of two newly opened ice rinks on an accident and emergency department. British Medical fournal 296, 96.

Prescott M.V. (1986) The effect of opening an ice-rink on the accident and emergency of a district general hospital. Archives of Emergency Medicine 3, 107-10.

Horner C. \& McCabe M. J. (1984) Ice skating and roller disco injuries in Dublin. British fournal of Sports Medicine 18, 207-11.

Biener V. K. \& Muller P. (1973) Eislaufunfalle-Epidemologie und prevention. Forschritte der Medizin 91, $185-6$.

Bernard A. A., Corlett S., Thomsen E., Bell N., McMahon A., Richmond P. \& Porter K. M. (1988) Ice skating accidents and injuries. Injury 19, 191-2.

Williamson D. M. \& Lowdon I. M. R. (1986) Ice-skating injuries. Injury 17, $205-7$.

Vincent C. A., Driscoll P. A., Audley R. J. \& Grant D. S. (1988) Accuracy of detection of radiographic abnormalities by junior doctors. Archives of Emergency Medicine 5, 101-9. 